\title{
Standards-Based Grading: an Examination of Assessment Options
}

\author{
Amy E. Mcbride, Ph.D \\ University of Evansville \\ School of Education \\ 1800 Lincoln Ave \\ Evansville, IN 47722, USA \\ And Jared Kahle \\ University of Evansville \\ School of Education \\ 1800 Lincoln Ave \\ Evansville, IN 47722, USA
}

\begin{abstract}
Methods of assessing and measuring student learning have long been examined for their effectiveness in providing valid and reliable reports. While letter grades have historically been the traditional system of grading and the common choice of educators and parents, the growing importance of standards-based instruction has created a need to rethink options. There are challenges to all options of assessment however, evaluating student growth through the use of a standards-based grading system is reported to provide more clarity and value to the process of assessment.
\end{abstract}

Keywords: standards-based, grading, assessment and measurement

"A profound cultural transformation [would be] classrooms in which both students and teachers focus on learning, not grades" (O'Connor, 2009, p. 1). Grading and reporting are essential elements of any educational establishment and represent student performance through teacher analysis. Due to the fundamental need for grades in both tracking and reporting student performance, educators must make sure grading and reporting is valid and reliable. In addition, grades act as link between educators and caretakers, in order to ensure that grading and reporting maintain meaningfulness, accuracy, and fairness (Munoz \&Guskey, 2015). This paper will discuss the purpose of grading, traditional grading systems, and standards-based grading.

\section{The Purpose of Grading}

Grades have always held a variety of purposes, yet it was clearly recognized that grading and reporting was a critical part of learning. O'Connor (2009) identifies four general purposes for grades within educational facilities: Instructional, Communicative, Administrative, and Guidance. Grades are used for instruction to clarify learning goals and indicate students' strengths and weaknesses. They provide information regarding the personal-social development of students and are a form of motivation. As a communicative tool, grades inform parents or guardians about the progress of their children toward reaching intended learning goals. Administration utilizes grades as a method of reporting effectiveness to the community and determining merit. Finally, grades are used to guide students in making their educational and vocational plans. This broad expanse of purpose created a limited value of grades from an accountability stand point because the letter grade had to carry so many types of information (O’Connor, 2009).

The variety of purposes for grades caused teachers to utilize an array of grading criteria which developed a disconnect between understanding of student achievement and what a grade represented. This also led students to become misinformed about the criteria upon which grades were based as they transitioned classes, grade levels, and schools (Munoz \&Guskey, 2015). Along with grades having served countless purposes, teachers often assessed many different criteria to formulate a single grade which caused discrepancy among students' grades and blurred their meaning. Ultimately, grades had a tendency to not effectively communicate to the students, teachers, or institutions (Hooper \& Cowell, 2014). 
As educators began to recognize the vague meaning of grades due to the multiple forms of information represented, they began assigning multiple grades which supplied the foundation for standard-based grading (Munoz \&Guskey, 2015).

O'Connor (2009) stated, "official guidelines on grading are often vague, nonexistent or ignored" (p. 1). There were a multitude of factors hindering change, but it was transparent that change must have occurred in the way grades were taken and reported. Guskey and Bailey (2009) found three important reasons for constructing an immediate change in this area. These reasons were outlined as grading and reporting being inadequate, misaligned with current reform, and developing new procedures often prompted discussions that lead to student success (Guskey\& Bailey, 2009).

Traditional grading persisted in schools merely because educators and stakeholders had not considered the limitations or vagueness despite the major effects even minuscule alterations to grading processes had on student development. This lack of alteration caused the reporting of grades to become misaligned with educational reform. As schools worked to align teaching with standards and student proficiency, the reporting of grades had been omitted and did not distinctly portray student progress (Guskey\& Bailey, 2009). As these shifts occurred it was crucial that there were more compatible grading procedures implemented that put a prominent focus on learning rather than collecting points (Reeves, 2007). This led to the further discussion of educational practices which was critical to student growth and progress. A thought process regarding a process to report student proficiency steered teachers to question clarity of standards, instructional effectiveness, as well as a multitude of other educational practices (Guskey\& Bailey, 2009). This questioning directed a refinement and enhancement in all educational practices. "In a perfect world there would be no grades - at least as we know them now" (O'Connor, 2009, p. 1).

\section{Traditional Grading Systems}

Grading systems were the central reporting system used to communicate student achievement to students and others beyond the classroom. The sole purpose of grades was to monitor and communicate student achievement within the classroom. Traditionally grading systems had been based on an A - F letter grade system in which educators reported a single grade for a content area to each student. These grades were procured through averaging multiple assignments, quizzes, projects, and tests as well as nonacademic criteria such as participation, effort, attendance, and assignment punctuality. These averages translated into letter grades in a variety of ways but most familiarly as follows: $\mathrm{A}=90-100 \%,=80-89 \%, \mathrm{C}=70-79 \%, \mathrm{D}=60-69 \%$, and $\mathrm{F}=$ Below $60 \%$ (Hooper \& Cowell, 2014). In addition, grades were communicated in a broad variety of methods.

Grading systems existed in a variety of forms; presenting criteria in different formats which created fractures in the meaning of these grades. Educational institutions used systems including the following: pass/fail, letter grades, and numerical scores. The most common of these systems were letter grades. Letter grades were seen from a three to five-point scale as follows:

- 3 Point Scale - Excellent, Satisfactory, Needs Improvement

- 4 Point Scale - High Pass, Pass, Low Pass, Incomplete

- 5 Point Scale - A, B, C, D, F

These scales were all symbolic representations of student achievement but encompassed a broad range of information within that symbol. The three-point scale was generally applied when working with younger learners. The four-point scale developed into more levels and was designed to boost student confidence and attitudes by not having a failing grade. Five-point scales added the component of failing to the scale and became the most commonly used (O’Connor, 2009).

Despite the familiar grading scale shown above, schools and teachers often had the autonomy to set averages for the scale. This lack of consistency created accuracy issues across schools and teachers and the meaning of the grades that were reported (O'Connor, 2009). Hooper and Cowell (2014) reinforced this concept when discussing the ways educators assessed. They discovered that within traditional grading systems there was not a clear and agreed upon criteria which students were measured (Hooper \& Cowell, 2014). Traditional grading amassed a multitude of concerns about how and if these systems were truly providing quality results that were beneficial. When referring to grades Reeves (2007) stated, "They rely on a traditional approach to grading - adding up scores and then calculating a grade - which is often counterproductive to the objective of learning for all" (p. 127). Traditional grading fell short by being vague and subjective. 
Since scores were averaged based on assignments, the letter grade failed to communicate what each student actually knew. Hooper and Cowell (2014) referenced two students who had the same average score. One student earned a $64 \%$ on every assignment completed while the other received an $80 \%$ on all assignments but two (scored a 0 on these). This demonstrated that the second student clearly had a greater mastery of the skill but final grades showed the two at the same proficiency level (Hooper \& Cowell, 2014). This computation of scores again fabricated vague results.

These grading systems also demonstrated shortcomings when academic grades were lowered for no academic misconduct. O'Connor (2009) referenced teachers as including "ability, effort, attitude" (p. 38) as well as other non-academic measurements in student grades. These non-academic factors lowered grades without having been connected to student mastery of classroom content. O'Connor (2009) continued to testify that criteria should have consisted only of the most highly valued variables and those variables should have designated the achievement on a specific learning goal. These different areas, in order to communicate information in a useful manner, should have been reported separately (O'Connor, 2009). Shippy (2013) supported this by saying, "students should be graded solely on mastery of course content" (p. 1). With these issues resolved grading shifted the focus from point accumulation to the process of learning.

\section{Proficiency Standards}

Standards came to the forefront of the educational world and continued to remain the center for progress in classrooms, but how were students being measured on progression of these standards? The answer was identified through establishing proficiency or performance standards. The challenge occurred when defining what level of proficiency was required or suitable for each standard or set of standards (Nevi, 1997). In regard to setting proficiency or performance standards, Koffler (1980) stated, "Each method is unique in its derivation, yet all possess a common quality: all standard setting is judgmental" (p. 167).

There are a number of approaches available when determining student proficiency. When outlining a proficiency model, O'Connor (2009) stated that there were no fewer than four and no more than ten measures of quality. A pure standard-based grading system had only two levels, mastery and not proficient, but it was beneficial to use more indicators to show student progression on the standard. Conley (2000) reinforced the need and benefit of proficiency standards with a five-point scale used to determine student performance. The levels of Conley's scale were: Exemplary, High-Level mastery of the proficiency, Meets the proficiency, Working toward the proficiency, and Not meeting the proficiency. As Conley (2000) analyzed the use of proficiency versus the use of traditional grades in school, there was little connection between proficiency and the traditional grading systems being used by teachers. The grading systems illustrated little or no evidence of student proficiency on specific standards. This indicated that grades were analyzing something other than student proficiency on the standards being taught in schools.

These grades were not representative of student proficiency on standards; yet as the focus of teaching became more greatly influenced by standard reform, one had to consider reforming the grading system. Proficiency developed a transparent view of student mastery of standards which allowed educators a more precise view of student skills (Guskey\& Bailey, 2009). Through proficiency standards a standard-based grading system naturally formulates. O'Connor (2009) referenced an eight year old student saying, "Show us what good work looks like and what we have to do go get there" (p. 82). Proficiency standards fostered a system that developed a clear understanding of "good work" as well as a path to get there (O'Connor, 2009).

\section{Standard-Based Grading}

"Grading according to standards, competencies, or concepts is nothing new. With the current grading system gaining more scrutiny, parts of the basic framework of how we grade students are being questioned" (Shippy, Washer, \& Perrin, 2013, p. 1). As the push for standards increased many educators began integrating these concepts into grading processes naturally. By recognizing these changes and approaching reform through small changes rather than a major shift, educators were able to formulate grading systems that reported an accurate display of academic student achievement (Shippy, Washer, \& Perrin, 2013). These natural adjustments supported the use of standard-based grading. Reeves (2007) recognized grading through eight guidelines that depicted the differences between traditional and standard-based grading systems. These guidelines profiled the way standardbased grading created a more accurate vision of academic achievement for students, allowing for greater communication between teachers, students, and parents. 
It also demonstrated the way standard-based grading systems provided feedback on student strengths and weaknesses while assisting the educator to adjust instruction to the explicit needs of students. Guskey and Bailey (2009) supported the need for a more accurate and distinct grading system by saying, "Researchers also contend that inclusion of these nonacademic factors in determining students' grades is responsible, at least in part, for the discrepancies frequently noted between students' grades and the students' performance on large-scale accountability assessments" (p. 6).

Scriffney (2008) presented seven reasons the shift in reporting grades should have been toward standard-based grading. They were as follows: 1) Grades should have meaning, 2) To challenge the status quo, 3) Control grading practices, 4) Reduces meaningless paperwork, 5) Helps teachers adjust instruction, 6) Teaches what quality looks like, and 7) Launchpad for other reforms. As displayed, the traditional grading system did not support a clear and accurate meaning for grades (Scriffiny, 2008). Munoz and Guskey (2015) contended that the purpose of grading was to report specific progress on learning targets and communicate that information to students, teachers, and parents. In order to have fostered a system that provided meaning for grades while still valuing the nonacademic areas, educators must have established product, process, and progress indicators and supplied separate grades for each section. This allowed for a clearer and more comprehensive image of achievement while recording responsibility, effort, attendance, and other nonacademic indicators (Munoz \& Guskey, 2015).

Scriffiny (2008) also referenced challenging the status quo and the ability to control grades as reasons for standard-based grading. The ability to control grading created the challenges to the status quo in education by leading classrooms to incorporate these changes in an attempt to assist in the learning process. By changing homework and tests in a way that each problem was directly connected to a proficiency standard, educators shifted from norms within the classroom while maintaining clear and accurate reporting (Scriffiny, 2008). Altering the purpose and structure of assignments created a learning environment that "provides families with the specific feedback they require to ensure that improvement efforts are appropriately focused and more likely to succeed" (Guskey\& Jung, 2009, p. 54).

Standard-based grading also reduced paperwork, helped adjust instruction, and provided students an appropriate sample of quality work. This grading approach allowed teachers the opportunity to have gleaned the most out of every assignment students completed, which allowed for a comprehensible grasp of student progression on specific skills. As teachers analyzed this proficiency focused work, they were able to recognize the progression of the class and the amount of time saved on previously wasted assignments (Scriffiny, 2008). Reeves (2007) supported this in stating, "Teachers should provide feedback on formative assessments (those assessments for learning such as drafts, quizzes, and practice), but determine grades only from the evidence from varied summative assessments (assessments of learning)" (p. 138). In doing this educators removed the mentality that everything students did must have produced a grade. In turn this permitted educators to focus on adjusting instruction in a way that better served students. This then allowed students and parents to see learning as a process examining what quality looked like and individual progression toward proficiency (Reeves, 2007). As educators made this transition in teaching, grading, and reporting, it acted as a launchpad toward reform (Scriffiny, 2008).

\section{Parents and Standard-Based Grading}

Despite the growing influence of standards within daily instruction and the development of more educators expressing a need for reform in reporting grades, there were still challenges in acquiring external support. In regard to this Guskey and Bailey (2009) found: Occasionally parents express skepticism about standards-based report cards. They believe that a traditional letter grade or percentage grade for each subject on the report card works just fine; and they see no reason to change. Parents also understand letter grades, or at least they believe they do, because letter grades were used when they were in school. (p. 6)

It was difficult to accept these changes in grading and reporting due to personal background in the way parents experienced grading. School policies, tradition, and college programs also dictated beliefs about grading practices (Shippy, Washer, \& Perrin, 2013). 
In addition, since most colleges and universities use letter grades and will probably continue to do so, parents want their children to become accustomed to letter grade systems. So that they can successfully navigate within such systems when they reach that level. (Guskey\& Bailey, 2009, p. 6)

This situation placed the responsibility on educators to encourage parents to break tradition and realize the shortcomings of traditional grading practices as well as the learning benefits created by standards-based grading (Guskey\& Bailey, 2009). In further support of this parent reaction to standard-based grading, Lubienski (2004), in a study of standard-based versus traditional grading in mathematics, reported, "Parents who chose the traditional sequence expressed more concern about college preparation, whereas parents who chose the Standards-based sequence placed a higher priority on student understanding and enjoyment of mathematics" (p. 338).

Parents from all backgrounds and environments wanted to help their children have high achievement in school and preferred more information about the growth and proficiency of their child. Educational institutions had discovered that parents favored more information more often, and saw the reporting of grades as the primary source of this communication (Guskey\& Bailey, 2009). Parents clearly had apprehensions toward standard-based grading; however, the desire to have additional information and accurate reporting led toward this grading system. Parents who had been exposed to standard-based grading found it to be an advantageous way of reporting student achievement (Swan, Guskey, \& Jung, 2014).

Swan, Guskey, and Jung (2014) studied parents' reactions to the implementation of a standard-based grading system. Having examined the desire of parents to have more information regarding student progress, it was natural that the study revealed parents had a positive response to the reporting method. Parents found the reporting system to provide "more information and better-quality information than the traditional report card" (Swan, Guskey, \& Jung, 2014, p. 296). The response of parents was very positive, but tradition and personal experience with grades still restricted parents in their responses. Parents still aspired for a percentage to accompany the standard-based grading that was received, expressing that they understood what a 97 meant (Swan, Guskey, \& Jung, 2014). This showed that the challenge in reforming grading occurred in breaking tradition and personal belief about grading which put the responsibility on educators to bridge these gaps.

\section{Teachers and Standard-Based Grading}

"Teachers are often very sensitive about their grading practices - they regard them as sacred ground" (O'Connor, 2009 , p. 1). Teachers were at the center of grading and reporting systems and were vital to the progress of developing systems that were more specific and better communicated helpful information. When examining teacher reactions to the grading process, similar challenges were recognized. Teachers were also facing the problem of tradition and personal belief about grades and how they were reported as well as maintaining fairness (Swan, Guskey, \& Jung, 2014; Tierney, Simon, \&Charland, 2011).

Teachers were found to implement personal alterations to grading practice in order to keep fairness and maintain personal pedagogy. Tierney, Simon, and Charland (2011) noted: When teachers were asked directly about grading principles, they responded in two ways. Some referred to principles that were not specifically related to grading, but that guide fair assessment in general terms. For example the idea that students should have ample opportunity to learn was stated by several participants. (p. 211)

Educators seemed more concerned about fairness and did not view principals of grading as bared in the following example: "One participant tepidly agreed that he followed grading principals based on his interpretation of an OME grading policy" (Tierney, Simon, \&Charland, 2011, p. 211). These findings demonstrated the importance of a clearly outlined system for implementing standard-based grading.

In the study by Swan, Guskey, and Jung (2014), teacher reactions and opinions about standard-based grading were also reported. As with parents, teachers also demonstrated challenges in breaking from personal belief or tradition in grading. Teachers expressed desire for more accurate reporting of grades that provided more information and higher quality information. In the study, teachers who volunteered were naturally revealed to observe stronger value than teachers without experience in standard-based grading. Despite the findings that teachers found the reporting system to have provided more information, parents had a more positive reaction to the new system (Swan, Guskey, \& Jung, 2014). 
Another challenge presented to teachers was the added time spent on reporting in a standard-based grading system. In response to the time teachers spent reporting grades, Swan, Guskey, and Jung (2014) noted: They also reported that the standards-based reporting process was more time consuming, but that the value added was worth the additional time. One teacher indicated that it took them approximately two to three hours to complete the reports, but that they felt it was a reasonable amount to ask from teachers. The increased time is not surprising as these classrooms were moving from providing a single composite score to providing several scores in addition to narrative. (p. 296)

This additional time may have produced challenges with teachers who were not volunteering to make the move toward the utilization of standard-based grading. Again the study displayed that teachers, like parents, struggled with breaking traditions with grading until the results of a new grading method were witnessed.

\section{Conclusion}

"Grading and reporting student achievement is a caring, sensitive process that requires teachers' professional judgement" (O'Connor, 2009, p. 1). There was a clear and significant difference between the information that was displayed in traditional grading systems versus standard-based grading systems. The results reported positive aspects of standard-based grading, showing more clarity and value in grading; however, challenges as with any grading system were still prevalent. As educators it was essential to continue working to provide students with the best learning opportunities available.

\section{References}

Conley, D.T. (2000, April). Who is proficient: The relationship between proficiency scores and grades. Paper presented at the annual meeting of the American Educational Research Association, New Orleans, LA. (ERIC Document Reproduction Service No. ED445025)

Guskey, T. R., \& Bailey, J. M. (Eds.). (2009). Developing standards-based report cards.Thousand Oaks, CA: Corwin Press.

Guskey, T. R., \& Jung, L. A. (2009). Grading and reporting in a standards-based environment: Implications for students with special needs. Theory Into Practice, 48(1), 53-62.

Hooper, J., \& Cowell, R. (2014). Standards-based grading: History adjusted true score. Educational Assessment, 19(1), 58-76.

Koffler, S. L. (1980). A Comparison of approaches for setting proficiency standards. Journal Of Educational Measurement, 17(3), 167-178.

Lubienski, S. T. (2004). Traditional or standards-based mathematics? The choices of students and parents in one district. Journal Of Curriculum And Supervision, 19(4), 338-365.

Muñoz, M. A., \&Guskey, T. R. (2015). Standards-based grading and reporting will improve education. Phi Delta Kappan, 96(7), 64-68.

Nevi, C. (1997). A modest proposal for establishing proficiency standards. National Association of Secondary School Principals NASSP Bulletin, 81(588), 115-117.

O’Connor, K. (2009). How to grade for learning, K-12 (3rd ed.). Thousand Oaks, CA: Corwin Press.

Reeves, D. B. (2007). Ahead of the curve : The power of assessment to transform teaching and learning. Bloomington, IN: Solution Tree.

Scriffiny, P. L. (2008). Seven reasons for standards-based grading. Educational Leadership, 66(2), 70-74.

Shippy, N., Washer, B. A., \& Perrin, B. (2013). Teaching with the end in mind: The role of standards-based grading. Journal Of Family And Consumer Sciences, 105(2), 14-16.

Swan, G. M., Guskey, T. R., \& Jung, L. A. (2014). Parents' and teachers' perceptions of standards-based and traditional report cards. Educational Assessment, Evaluation and Accountability, 26(3), 289-299.

Tierney, R. D., Simon, M., \&Charland, J. (2011). Being fair: Teachers' interpretations of principles for standardsbased grading. The Educational Forum, 75(3), 210-227. 